\title{
Koesister op 'n Royal Albert piering: 'n Kritiese nabetraging van 'n nie-moedertaalonderwys- ervaring
}

\author{
Rinelle Evans \\ Departement Geesteswetenskaplike Onderwys \\ Universiteit van Pretoria \\ E-pos: rinelle.evans@up.ac.za
}

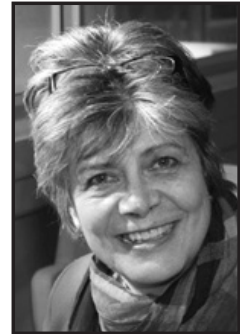

Rinelle Evans
Rinelle Evans is mede-professor in die Fakulteit Opvoedkunde, Universiteit van Pretoria. Sy is tans betrokke by onderwyseropleiding en fasiliteer modules wat verband hou met geletterdhede, kommunikasievaardighede en taalonderrigmetodologie. Sy het 'n doktorsgraad in kurrikulum- en onderrigontwerp met spesiale verwysing na onderrigkommunikasie via televisietegnologie. Sy het ook 'n meestersgraad in die onderrig van Engels as 'n vreemde taal verwerf aan die Universiteit van Birmingham, Engeland. Sy is ' $n$ NNS-gegradeerde navorser en lei tans 'n navorsingsprojek wat verband hou met die vlak van voornemende onderwysers se vermoë om in Engels onderrig te gee. Sy is nasionale voorsitter van die Suid-Afrikaanse Vereniging vir Taalonderrig en (mede)-outeur van verskeie akademiese en nie-akademiese publikasies wat verband hou met taal-in-die-onderwys vraagstukke. Sy ontvang ook verskeie onderwystoekennings vir uitmuntende onderrig.
Rinelle Evans is an associate professor involved with teacher education and she facilitates modules related to literacies, communication skills and language teaching methodology in the Faculty of Education, University of Pretoria. She holds a doctorate in curriculum and instructional design with special reference to instructional communication via television technology. She also obtained a Masters degree in teaching English to speakers of other languages from the University of Birmingham, England. She is an NRF rated researcher and is currently leading a project related to pre-service teachers' ability to teach in English as a medium of instruction. She is the national chair of the South African Association of Language Teaching and (co-) author of several academic and non-academic publications related to language-in-education issues. She is also the recipient of several awards in recognition of teaching excellence.

\section{OPSOMMING}

Keuses wat omgee-ouers uitoefen word gewoonlik met die beste bedoelings gemaak, maar het dikwels onvoorsiene gevolge. Min ouers deurdink die kritieke rol wat taal in 'n komplekse omgewing soos die klaskamer speel. Sommige glo ook dat 'n onderrigtaal bloot 'n leivoor is vir die oordrag van kennis, en is nie altyd bewus van die sterk, tog onsigbare verbintenis tussen die skool en die huisomgewing nie. 
My mededelings versteur moontlik die meningsekwilibrium wat talle ouers tans ten opsigte van 'n onderrigtaal mag huldig. Dit is egter noodsaaklik dat 'n verreikende besluit soos die keuse van 'n skool - veral vir aanvangsleer - nie bloot op grond van die onderrigtaal gemaak word nie. Aan die hand van 'n persoonlike taalbiografie word verskeie mites rakende die rol van taal, kultuur en identiteit in die onderwys krities bekyk.

TREFWOORDE: Taalbiografie, nie-moedertaalonderrig, taalbeleid, taalvoorkeur, taalgolwe, parallelmediumskole

\section{INLEIDING}

Die huidige taal-in-onderwyssituasies is kompleks en is hoofsaaklik gekoppel aan Suid-Afrika se taalgeskiedenis. Dit is egter ook nou verwant aan binnelandse migrasie, gesindhede en persepsies heens verskeie landstale, asook streeksverskille en plaaslike variëteite. Provinsiale regerings het 'n beleid aanvaar dat Engels plus die twee tale wat as gesprekstaal die algemeenste gebruik word in die streek, sal dien as algemene voertaal; ook in skoolverband.

Die Grondwet bied aan elf amptelike tale "gelykheid van aansien" en vereis dat elk billik behandel word. Landsburgers is dus geregtig daarop om hul moedertaal vir alle redelike doeleindes te gebruik. Praktykwerklikhede en kostes keer egter dat hierdie bepaling binne die klaskamer effektief voltrek kan word. Die Grondwet waarborg dus nie dat al elf tale ewe veel gebruik sal word nie. In stedelike gebiede is dié taalsaak veral kompleks aangesien daar so 'n sterk diversiteit binne gemeenskappe voorkom en dit het tot gevolg dat die Suid-Afrikaanse klaskamer ten opsigte van taalsamestelling lank nie meer homogeen is nie. Ondeurdagte mediaberigte stook voorts verkeerdelik die imperalistiese vuur vir Engels as voorkeurtaal. Die huidige werklikheid dui dus daarop dat baie ouers Engels verkies as die uitsluitlike taal waarin hul kinders tans onderrig moet word.

Histories het Engels nog altyd in Suid-Afrika 'n hoë aansien geniet; beide onder koloniale en apartheidsbewind. Dat die gebruikswaarde van hierdie taal toenemend verhoog en die gebruik daarvan nog wyer versprei, pas netjies in by die kontemporêre nasionale doelwitte om 'n ras-geïntegreerde nasie te bevorder (Malan 2012). Daarmee saam word voorsien dat Suid-Afrika ekonomies met gemak die internasionale verhoog kan betree. ${ }^{2}$ Die logiese gevolg is dus dat die huidige onderwysbeleid, wat die taalbeleid insluit, poog om te verseker dat leerders 'n breër samelewingskonteks kan ervaar wat gepaardgaan met die politieke en ekonomiese voordele wat die bemeestering van 'n internasionale taal soos Engels bied.

Menigte ouers en versorgers verkies Engels sonder om die omvattende taalkompleksiteite van die klaskamer ten volle te begryp; dit is ook duidelik dat hulle onbewus is van deurdagte navorsingsbevindinge wat die akademiese voordeel van die huistaal as onderrigtaal inhou, terwyl daar tog doelbewus toegang tot Engels of ander dominante tale soos Frans, Spaans en Portuguees of selfs Mandaryns geskep word om sodoende internasionale deelname te verseker. ${ }^{3}$ Hierdie toegevoegde tweetalige benadering word wel tans in beleidsdokumente aangemoedig, maar word nie in die praktyk ondersteun nie.

Selfs voor die aanbreek van 'n demokratiese era in 1994, kon Afrikaanssprekende ouers sedert 1910 kies tussen Afrikaans of Engels as onderrrigtaal. Die huidige nasionale Grondwet

Suid-Afrikaanse Grondwet (1996) par 6 (4): 4

Republic of South Africa (2010); Republic of South Africa (2001:38); Crystal (2003); Heugh, Siegrühn \& Plüddemann (1995); Tollefson (1991); Tollefson \& Tsui (2004).

3 Bunyi (1999); Cummins \& Hornberger (2007); Holmarsdottir (2005); Wong-Fillmore (1991).

Tydskrif vir Geesteswetenskappe, Jaargang 57 No. 3: September 2017

doi.10.17159/2224-7912/2017/v57n3a2 
(1996) en Taal-in-onderwysbeleid (1996) maak weer voorsiening vir wat deur baie as 'n burgerreg geëis word maar deur vele ook as 'n luuksheid en diskriminerende praktyk beskou word. Moedertaalonderrig verskans en bevoordeel steeds slegs Engels- en Afrikaanssprekende leerlinge aangesien hulle tans nog vanaf voorskool tot op nagraadse vlak onderrig kan ontvang in 'n taal waarin hulle gemaklik dink en doen. Hierdie voorreg wankel egter in die huidige hoëronderwysomgewing, selfs in skole wat voormalig in Afrikaans onderrig aangebied het omdat die leerderdemografie sodanig verander het dat Engels as voertaal ingestel is, en nou selfs as enigste medium van onderrig dien.

Baie Afrikaanssprekende ouers neem hierdie bestel wat merendeels nog in die laerskool geld vanselfsprekend, en glo dat dit voordeliger is om hulle kinders - veral met aanvangsleer - in 'n nie-moedertaalomgewing te plaas. Hulle voer aan dat hoe vroeër hulle kinders Engels leer praat, hoe beter. Hierdie wanopvatting negeer die ongesiene, maar sterk sosio-kulturele invloed wat 'n voertaal uitoefen.

\section{PERSOONLIKE NARRATIEF}

In hierdie stuk bekyk ek krities, aan hand van my persoonlike taalbiografie en skoolervaring, die blywende invloed van nie-moedertaalonderwys, en belig daaruit etlike wanopvattings.

\subsection{Brits en Franse voorvaders}

My taal- en kultuurerfenis is soet-vervleg uit twee hoofstrome:

Ten eerste, aan vaderskant 'n direkte Britse (Walliese) lyn: My oupagrootjie, Edward George Evans, is deur Charles Haddon Spurgeon, 'n baie invloedryke Viktoriaanse gereformeerde teoloog opgelei. Hy seil in 1883 vanuit Bristolhawe om as een van die eerste Baptiste predikante in suider-Afrika in die Grahamstad omgewing, die Oos-Kaap setlaargemeenskap te bedien. Die kerkie van sy eerste landelike gemeente - waar hy uiteraard in Engels die Woord verkondig het - staan vandag as 'n nasionale monument in die Kariega distrik. Die heel eerste van my afstammelinge wat op Suid-Afrikaanse bodem gebore is, kon nie die felheid van Afrika trotseer nie, en sy eersteling, Majorie Elizabeth, lê sedert 1886 - 1/2 meter lank - daar in die kerkhof se rooi klei.

Sy oudste seun, Charles Stanford Evans (1902-1966) - my Grandpa - was 'n bosbouer en het in verskeie dele van ons land op bosboustasies diens gedoen. Hy trou met my Granny Elizabeth - 'n nooi Robinson. Hulle gesin van vyf kinders word eg Engels grootgemaak. Uncle Philip het hom as veldwagter in die destydse Rhodesië gevestig, Aunty Elize is Amerika toe terwyl die ander twee tannies in Durban verpleeg. Almal is baie sterk Engels georiënteer, en trou ook later Engels.

Die oudste - my pa, Edward Philip - is uit Louis Trichardt se parallelmedium laerskool, Pietersburg (nou Polokwane) toe waar die naaste (Afrikaanse, uitsluitlik wit) hoërskool was. Hy behaal in 1951 aan die Universiteit van Stellenbosch, 'n MSc-graad in Genetika en wy sy hele loopbaan aan die hoofsaaklik Afrikaanse Nasionale Party se staatsdiens. Vir bykans dertig jaar, ry hy daagliks met die staatsdiensbussie op die Molotopad uit na die navorsingsinstituut te Roodeplaat net buite Pretoria en word in 1983 verplaas terug Matieland toe om verder op Nietvoorbij nuwe tafeldruifkultivars te skep. Sy tweetaligheid het hom wel later jare geloon aangesien hy in 1988 deur die (Nasionale Party) regering as Landbouraadgewer in Londen aangestel is om op daardie tydstip van felle ekonomiese boikotte en wêreldhoon, SuidAfrikaanse vrugte op die Europese markte te kry. 
Aan moederskant, vloei dit pure Franse Hugenote bloed aan beide kante terug tot by die heel eerste aankomeling, Charles Marais, wat in 1688 tesame met sy vrou, Catherine en vier kinders op die "Voorschoot" in die Kaap de Goede aangekom het. Hulle nakomelinge vestig hulle in die volgende 200 jaar as wingerdboere en poog om onder die sterk Hollandse invloed hul taal en kultuur te handhaaf - tevergeefs. My oupa - David Jacobus Roux Marais - is in 1893 gebore, die oudste van vier seuns. Maar teen 1899 bevind hy hom in 'n Vrystaatse konsentrasiekamp waar my oumagrootjie aan tering oorlede is. As Afrikaanssprekende, begin hy later sy naskoolse opleiding met 'n onderwysbeurs aan die University College te Bloemfontein. Hy studeer ook privaat in die regswese en word aangestel as privaat sekretaris van die Minister van Landbou. Hierna werk hy vir die regsfirma - Rooth and Coxwell in Louis Trichardt.

My Oumie, Catharina Maria (gebore Pienaar), studeer ook as Afrikaanssprekende in Engels aan die Hugenote Seminary, gestig in 1874 te Wellington - wat sy lewenslank as die Kaapse Kolonie beskryf het. Miss Pienaar kwalifiseer in 1910 as "kindergarten" onderwyser. Haar versameling getuigskrifte en opleidingsertifikate wissel tussen "heeft dit examen met goed gevolg afgelegd" en "This is to certify that ...". As jong juffrou, beklee sy onderwysposte in Oos Londen, Greylingstad en toe Louis Trichardt waar sy in 1922 in die huwelik tree met Oupa David. Hulle is eers in 1931 met 'n eerste en enigste geseën - Catharina Pienaar Susanna Marais.

My moeder is op 12 jaar, uit die Afrikaanse klas van Laerskool Louis Trichardt, Johannesburg toe na Parktown Girls' High - en word uit University of Witwatersrand 'n fisioterapeut. Haar ouers het hierdie hoë prys van trek-en-weer-begin betaal omdat, veral Oupa David geglo het dat 'n Engelse opleiding in daardie tyd net na die Tweede Wêreldoorlog, met 'n Smutsregering aan bewind, waarde sou toevoeg tot hul enigste kind se toekoms.

My ma het ook 'n jaar lank in Engeland se hospitale gewerk alvorens sy en my pa se paaie weer in 1952 gekruis het. Beide was dus volkome tweetalig toe hulle trou. My ma verlaat egter die NG kerk en laat haar "groot" doop as lidmaat van die Baptiste kerk. Pa se Afrikaanse werkskring verwater verder sy Evansgeit en hy "verboers" soos daar gesê was terwyl Ma alreeds as tiener begin verengels het alhoewel sy tot haar ma se dood net met haar Afrikaans gepraat het.

\subsection{Kleintyd}

Uit hierdie "gemengde" huwelik volg toe vier kinders. As oudste, is ek drie jaar lank die enigste, en praat slegs Engels. Ek beskou dus my eerste taal as Engels alhoewel dit tegnies nie my moeder se taal was nie. Ek beroep my ironies genoeg dikwels op 'n Engelse spelwyse of uitspraak wat my ma gebruik as 'n norm vir standaard Engels omdat haar Engelse skool- en universiteitsopleiding nog pure Brits-koloniaal was - 'n "hot potatoe” Engels nog onaangeraak deur die tongval van die verskeidenheid mense wat dit vandag op eie bodem praat. Ek bly 'n rukkie by Oumie in Johannesburg terwyl my ma op die tweeling se aankoms voorberei. Kort na hulle geboorte het Oumie kom hand bysit en bly toe, seker onbepland, tot sy op 92 by ons, oorlede is. Dit is dan ook by haar wat ek my tweede taal begin ontwikkel het. Springbok Radiostories agtermiddag en nuusuitsendings saans, Jongspan en Huisgenoot deurblaai; ook al haar onderwysboeke, meeste ingevoer uit England, op haar enkele boekrakkie. Afrikaanse vriende spot my steeds oor my argaïese woordeskat wat kolonie, onverpoosd, draadloos, klein-huisie en teeplepel insluit, maar ek het darem al afgeleer om te vra Hoe heet $u$ ? Of Wat is $u$ nering?

Tweeling en jongste sussie is vir ' $n$ jaar Afrikaanse kleuterskool toe. Ek nie. Die vier kinders is almal gemaklik deur die naaste laerskool - Arcadia Primary. Hierdie was een van 
vier Engelse laerskole wat gedien het as voerskool vir Pretoria Girls of Boys High School. Die skooltjie is geleë skuins oorkant 'n Herbert Baker Anglikaanse kerk met straat-af 'n groot sieraad van 'n sinagoge. Oorkant was 'n pragtige roostuin waar ons paddavisse tussen die waterlelies in die poele gevang het en moerbeiblare gepluk het vir ons sywurms.

Diversiteit is nie 'n onlangse verskynsel nie. Op Arcadia Primary was die enigste gemeenskaplike deler ons velkleur: 'n baie groot Joodse, Griekse en Portugese gemeenskap, later aangevul deur Britse en Libanese immigrante was ons speelmaats met wie ons rek of tou gespring het, met 'n barsoog albasters teruggewen het of gelukbringertjies uitgeruil het. Ek en my broer het ook diens gedoen as "librarians" in die biblioteek en dus baie (Engels) gelees. Tydens godsdiensonderrig het die Rabbi die Joodse kinders kom haal vir hulle schule en die sillabus van destyds het al "Immigrant Afrikaans", dit wil sê Afrikaans wat as 'n vreemde taal aangebied is, ingesluit.

Uit hierdie verskeidenheid is ons in die sewentigerjare na 'n veel meer homogene Afrikaanse taal, kerk- en kultuuromgewing toe: Afrikaanse Hoër Meisieskool Pretoria en Afrikaanse Hoër Seunskool. Die NG Kerk Pretoria-Oos bedien parlementariërs uit spogBryntirion, en beide skole se "koshuisbrakke" - hoofsaaklik "sessiekinders" - dié wie se ouers al om die ses maande tussen Kaap en Pretoria vir regeringsake pendel. Boonop was beide skole enkelslagtig met 'n sterk inslag van wat as ideal vroulik/manlik en derhalwe 'n goeie vrou/man beskou word: "Ek sien haar wen, vir man, seun en broeder. Want haar naam is vrou en moeder!"

\subsection{Studentedae}

Op Tukkies is slegs my Engelse lesings in Engels aangebied. Ek worstel deur Pedagogiek en Sielkunde, maar verlustig my in die Afrikaanse en Franse letterkunde. As Primaria lei ek huisvergaderings en ontgroen en tugtig eerstejaars. Ek jool en jol soos studente wat in 'n koshuis inwoon kan - als in Afrikaans. As VSR kandidaat bewyer ek my vir beter samewerking tussen Engels- en Afrikaanssprekende studente. Nie 'n gewilde manifes vir daardie dae nie. Ek stuur pakkies en bemoedig ons "manne op die grens" met radioboodskappe op Troepie-Hoekie.

Op negentien, reël ek op eie houtjie per slakkepos 'n werksgeleentheid in Alsace, Frankryk waar ek as huishulp en kinderoppasser van vier seuntjies drie maande slegs Frans praat. Hierdie ervaring was grootliks die begin van my politieke ontwaking. Nie alleen het ek besef hoe op die agtervoet mens is sonder ' $n$ taal wat jy goed bemeester het nie, maar ek was ook geensins opgewasse om 'n ideologie wat ek kwalik bevraagteken het, op 'n hoër kognitiewe vlak te kon beredeneer. In die dae voor tegnologie veral visuele kommunikasie vergemaklik het, was die gesin oortuig daarvan dat hulle 'n geleentheid bied aan 'n onderdrukte Suid-Afrikaner om 'n rukkie te ontsnap uit 'n "polisiestaat", en veral die pa het my konstant uitgedaag en verbaal afgeknou. Ek kon danksy Watson se skoolhandboek plaasdiere in Frans benoem, maar my poging om die bestaan van ' $n$ tweevoudige stedelike vervoerstelsel en die indringende vrae oor hoekom daar nou juis rooi en groen busse was te verduidelik, het gefaal en het my ook blits-skielik en ongemaklik laat besef dat my Sunnyside-wêreldjie nie meer so regverdigbaar was nie.

Daardie ongemak van 'n toegedigde onderdukkeretiket het ek later jare meermale gevoel veral tydens besoeke aan die buiteland waar daar selfs op 'n keer aan my toegesnou is dat ek nooit 'n pos by 'n Britse taalskool sou kon beklee nie, want "your accent smacks of the previous regime"! As wenner van verskeie onderwystoekennings, was dit ironies dat my moedertaal en onderrigvermoë met een snedige opmerking ontken is, en dat al die "sondes van die voorvaders" gekoppel kon word aan 'n individu se tongval! Taalarrogansie van die hoogste waters! 


\subsection{Onderwysloopbaan}

My onderwysloopbaan begin in 1978 en draai deur platteland en stad waar ek die "Rooitaal" en Shakespeare aan Boertjies onderrig. Weerstand is sterk in die vroeë jare, maar geleidelik word vaardigheid in Engels uiters gesog. Ek ontvang nog jaarliks dankbare terugvoer van oudleerlinge wat oral in die wêreld werk of woon en wat hul waardering uitspreek vir dit wat hulle in die Engels-as-tweede-taalklasse geleer het wat hulle in staat gestel het om met selfvertroue in Engels (sonder die afsweer van hul moedertaal) 'n spektrum van professionele loopbane gemaklik te volg.

My tweetaligheid het my wel in my loopbaan al die jare goed te staan gekom, alhoewel afhangend van by watter skool ek vir senior poste aansoek gedoen het, het ek gereeld by aanstellingskomitees verneem dat ek of té Engels of té Afrikaans is. Hierdie "outsider" gevoel is dikwels geïntensiveer deur my onskuldige gebruik van woorde wat dubbelsinnig vertolk is of sterk belaai is met ondertone. Ter stawing: toe ek as langafstandatleet met 'n Union Jacksportbroekie geoefen het, merk een van my manlike kollegas op dat "Dis nou 'n vlag wat ek sal wil stryk!" My naïewe teenopmerking was "Maar dis dan nie gekreukel nie!" Ek weet nou beter van nasionale simbole wat gestryk en gehys word maar bedink tog my gebruik van woorde wat met vlerke of nate verbind kan word!

Tans in die tersiêre omgewing wend ek my tweetaligheid en ryk kultuurervarings gemaklik aan en bereik daardeur 'n veel breër onderwysgehoor. Ek begryp ook so goed ander se stryd om in 'n nie-moedertaal omgewing te wil vorder. Ek bevind my nou in die demokratiese era waar diversiteit (oftewel "andersheid") verdra word, vir die eerste keer, minder van 'n randfiguur.

\subsection{Sibbe se lewensdraaie}

Broer was 'n Junie-inname en verloor dus drie jaar aan diensplig voor hy kon inskryf by Wits. Hy praat nou baie selde Afrikaans. My jongste suster slaan van Normaal Kollege Pretoria oor na Pretoria College of Education waarna sy sewe jaar by 'n Engelse laerskool vir Graad 1's leer lees en skryf, veters vasmaak en neusies afvee. Sy verlaat in die middel 80's die land en woon al 30 jaar in Londen. Ander sussie trou met 'n stewige boerklong uit Dendron se omgewing waar sy pa 'n aartappelboer was. Marie-Louise verlaat die Baptiste kerk en katkiseer as volwassene in die NG Kerk waar hulle twee spruite ook gedoop is. My nefie, Jacques en niggie, Tarien begin 'n skoolloopbaan in Laerskool Theresa Park, maar die gesin emigreer en hul voltooi hul akademiese opleiding wel suksesvol tot op tersiêre vlak in 'n nie-moedertaal omgewing. Die makliker oorgang was grotendeels te danke aan Afrikaanssprekende onderwysers uit Bloemfontein en Natal wat beide kinders tydens hul eerste Kiwi skoolontmoeting gehad het. Marie-Louise het ook as onderwyserhulp kon insit en bystaan met vertaal en tolk. As gesin lei hulle in Auckland, New Zealand tans 'n emosionele ryk en rustige lewe (meestal in Afrikaans).

Ek onthou nie dat ons as kinders ooit met ons ouers Afrikaans gepraat het nie; ek onthou nie dat ons ooit met Oumie Engels gepraat het nie. Maar sy moes kon Engels praat - sy het dan by Dominee Andrew Murray se Hugenote Seminary haar onderwysopleiding gekry. Later jare het ek wel taalwisseling toegepas met my sibbe en ouers en vind deesdae dat my moeder op 86 weer Afrikaans as haar dominante taal gebruik alhoewel haar sosiale en kerklike ruimte steeds sterk Engels is. 


\section{PERSOONLIKE GEVOLGTREKKINGS}

Keuses wat omgee-ouers uitoefen word gewoonlik met die beste bedoelings gemaak, maar het dikwels onvoorsiene gevolge. Nou wat kan ons uit hierdie vertelling wys word?

Eerstens, daar is ' $n$ baie sterker verwantskap tussen skool- en huiservarings as wat algemeen aanvaar word en dit is soms dissonant. Ek was baie gelukkig op skool en moes 'n profiel van 'n aard gehad het - al was dit dan een van andersheid - want ek is tog verkies as dirigent, debatsvoorsitter en prefek. Ek het ook op provinsiale vlak vir Noord Transvaal aan landloop deelgeneem. Maar ek het nooit vaste maats of soos daar deesdae gepraat word, 'n bestie gehad nie. Daar was altyd 'n onderliggende gevoel van nie-deel-wees nie en ek-pas-nie-in-nie. Ek het nooit pouses by dieselfde groepie dogters gesit nie en het meermale in die biblioteek die koerante gaan lees. Die verlies en verwarring ten opsigte van waar ek sosiaal ingepas het, was verder voelbaar in dié opsig dat die ander meisies Voortrekkers was en ek 'n Girl Guide. Alhoewel ons almal Sondae kerk toe hoedens gedra het, het hulle Vrydaemiddae die Heidelbergse kategismus geleer en ek dié aand my Baptiste gemeente se Young Life koffiekroeg bygewoon.

$\mathrm{Na}$ universiteit, was twee van my groot liefdes beide leiers in die Ruiterwag. Een se oupa het die Gideon Scheepersprys vir jeugliteratuur geskenk, die ander se pa was 'n sodanige kabinetsminister dat ' $n$ gebou na hom vernoem is. Uiteindelik is harde, hartseer skeidingsbesluite geneem, al het die een gedink my Meisies Hoër en Dames Dinamiek verbintenis sou ons deurhak! Toe ek skoolgehou het, is daar lank na my verwys as die "trompoppie juffrou" (een van my buitemuurse verantwoordelikhede) of "daai Engelse juffrou". Ek reken Evans was net te Brits om oor Boere-lippe te trippel!

My sussies was ook "outsiders" en onthou nie hul skooldae met dieselfde nostalgie as ek nie alhoewel een nog skoolreünies bywoon. My broer het 'n vagevuur verduur by sy seunskool waar daar in daardie tyd met misnoeë neergesien is op 'n Charles David wat glad nie sport beoefen het nie en boonop musikaal hoogs begaafd was. Sy Engelse onderwysers het hom staande gehou. Twee jaar se dienspliggeboelie het sy sterk weersin in als wat Afrikaans was, versterk. "Die taal is gans die volk" is inderdaad in sy geval van toepassing (Malan 2014).

Tweedens, 'n onderrigtaal is nie bloot 'n leivoor vir die oordrag van kennis nie. Die verborge kurrikulum van 'n skoolomgewing is veral sterk op kultuuroordrag. Ek het baie Britse en selfs Amerikaanse kampvuur- en ligte liedjies geleer uit huis en laerskool, ek ken ook meeste van dié in die FAK sangbundel, al die psalms en gesange maar nie een Afrikaanse kerslied nie want die skool het mos teen daai tyd al gesluit. Ek ken die Afrikaner se geskiedenis: die GRA en taalstryde, die kaalvoettrek oor die Drakensberge, die kindervolkshelde en konsentrasiekampverhale, dié ken ek. Die wonder van Afrikaanse letterkunde is deur verskeie entoesiastiese onderwyseresse passievol ontsluit. Ek kon later jare selfs Adam Small se gedigte gebruik om Romeo and Juliet aan my matriekklasse voelbaar te verduidelik in terme van die destydse apartheidsbedeling.

Ek was egter totaal onthuts en het selfs gestry met Juffrou Holtzhausen toe sy verduidelik het dat CJ Langenhoven Die Stem geskryf het. Vertaal ja, het ek geglo want ek het dan "Ringing out from our blue heavens" eerste geleer! Die laerskool het my ook geleer van Sheffield steel, Manchester United se sokkerhelde, American Field Service en SACEE ${ }^{4}$ se speech festivals. Die gedigte en stories wat verwys het na daffodils, dandelions, snowflakes, en red-breast robins

South African Council for English Education 
het my min geraak tot ek self bevooreg was om in England, die Engelse landskap, gebruike en kultuur eerstehands te ervaar tydens die verwerwing van 'n Meestersgraad (cum laude).

Dalk was my bi-kulturele blootstelling juis in my onderwysloopbaan van waarde want ek het my leerders se wêreld beter begryp. Ek rangeer tans gemaklik tussen die kultuurgroepe op sosiale vlak tot so 'n mate dat baie mense by my -steeds Baptiste kerk - met my probeer Afrikaans praat. My Engelse aksent is vir seker beïnvloed deur jare se blootstelling aan Afrikaans aangesien persone in die buiteland my gereeld vra of ek Duits of Nederlands is! Maar ek dra dit trots as 'n sterk identiteitsmerker.

Derdens, taalvoorkeure wissel na gelang van politiese en ekonomiese faktore. Vir my pa was die naaste hoërskool Afrikaans, so ook universiteit want Grandpa was toe in Stellenbosch op Jonkershoek gestasioneer. Moeder word sosiaal ontwortel omdat Oupa geglo het dat die beste skoling Engels en stedelik is. In ons vier kinders se geval, was die keuse van onderrigtaal ook 'n politieke besluit, geldig vir die vroeë sewentigerjare. My sussie en haar gesin emigreer ook vir politieke redes om 'n veiliger en meer voorspelbare toekoms vir hul kinders te verseker met dieselfde persoonlike opofferings wat ouers deur al die eeue vir hul nasate maak.

Ek verwys na "taalgolwe" eerder as taalverskuiwings aangesien golwe 'n meer dinamiese veranderlike omskryf terwyl 'n verskuiwing 'n permanentheid voorstel. In Suid-Afrika bly die debat rakende die medium van onderrig smeulend aangesien veranderende beleide of gemeenskapsoortuigings konstant wissel. Hier word selde op merkbare nasionale skaal, wegbeweeg van een taal na 'n ander taal met die gepaardgaande blywende aanvaarding van 'n nuwe kultuur en identiteit. Dit is dus heel moontlik dat oor 'n dekade van nou, ouers weer anders gaan kies ten opsigte van die taal waarin hulle kinders onderrig moet kry (Evans \& Cleghorn 2014).

Die verhewe status van die heersende gebruikstaal beïnvloed beslis ouervoorkeur by die keuse van 'n onderrigtaal. Hoogenhout se pleidooi sou nie onvanpas wees in die post-1994 era waar Engels weer 'n opbloei beleef nie. Die verskil is egter dat dit nou twee honderd jaar later nie deur wetgewing afgedwing word nie maar ondeurdag bo die huistaal verkies word deur ouers en gemeenskapsleiers. Ek maan egter dat 'n getuigskrif in Engels geskryf en onder 'n Engelse skoolwapen gedruk nie op sigself die toekomsdeure oopmaak nie. Goeie Engelse kommunikasievaardighede moet gekoppel wees aan verskeie ander persoonseienskappe en blootstelling.

Min ouers deurdink die kritieke rol wat taal in 'n komplekse omgewing soos die klaskamer speel. Ek belig in die laaste maar belangrikste plek, die moontlike akademiese impak van nie-moedertaalonderrig en skets van die praktiese oorwegings waarvan ouers en omgeevolwassenes moet kennis neem.

Ek het op skool by die jaarlikse prysuitdeling groot-oog gesit en kyk vir dié wat goue medaljes ontvang het vir akademiese prestasies, en myself net nooit in hulle liga van slimgeit geplaas nie. Ek het wel geweet dat ek getrou gewerk het om 'n bestendige $60 \%$ gemiddeld te handhaaf. Ek het vroeg reeds baie gesukkel met Wiskunde, ten spyte van ouerlike ingryping. Antjie se "vasgetangens" het ek tydens elke tranedal so goed verstaan en die uiteinde van my onvermoë om kwadrate en kwadrante te bemeester was dat ek matriek met drie tale, Bybelkunde, Huishoudkunde en Biologie slaag. Een onderskeiding - vir Engels. Gemeet aan my latere akademiese vordering waar vier van my kwalifikasies (met gepaardgaande akademiese toekennings) in Engels verwerf is, en met meerdere kennis van hoe belangrik taal is by begripsvorming en denkprosesse, weet ek nou dat ek nie "som-dom" en bloot gemiddeld is nie.

Jim Cummins - 'n Kanadese spesialis op die gebied van tweetaligheid - tref reeds in die jare sewentig 'n duidelike onderskeid tussen Basiese Interpersoonlike Kommunikasievaar- 
dighede (BIKV) en Kognitiewe Akademiese Taalvaardigheid (KATV). Hierdie onderskeid belig veral duidelik die tydskaal wat betrekking het op die aanleer van gespreksvlotheid vir sosiale doeleindes in 'n addisionele taal in vergelyking met 'n akademiese bedrewenheid in daardie taal wat skolastiese vordering vergemaklik. Sy navorsing met veral immigrante kinders het gewys dat KATV tussen $5-7$ jaar neem om ten volle te ontwikkel in die onderrigtaal. Leerders het ook baie akademiese ondersteuning nodig om in te haal op hulle eweknieë wie se huistaal dieselfde is as wat in die klaskamer gebruik word (Cummins 1979, 1992; Thomas \& Collier 2011). Alhoewel nie sonder aanvegbaarheid nie, is daar breë akademiese konsensus oor die noue verband tussen taalvaardigheid en akademiese prestasie.

Ouers moet dus verstaan dat alhoewel hulle kinders gemaklik en oënskynlik vlot kommunikeer in Engels, hierdie "alledaagse taal" nie vakspesifiek is nie en ook nie hoë kognitiewe eise stel nie. Dit word aangeleer tydens informele blootstelling aan die taal en hoofsaaklik gebruik in konteksryke verbande waar interpersoonlike leidrade soos gesigsuitdrukkings, gebare, stemintonasie en ander paralinguistiese gedragslyne, begrip en effektiewe gesprekvoering vergemaklik. Hul kinders sal dus telefoongesprekke volg, aanwysings kan gee, 'n verkooptransaksie kan voltrek en selfs Engelse webwerwe of tydskrifte maklik kan lees. Maar goeie sosiale taalvaardigheid veronderstel nie goedontwikkelde KATV nie onontbeerlik vir akademiese vordering (Joubert, Bester, Meyer \& Evans 2013).

KATV is 'n gesofistikeerde, kognitiewe veeleisende taalvermoë wat in 'n formele akademiese omgewing ontwikkel tydens die blootstelling aan hoëvlak verduidelikings, of uiteensetting van vakinhoude. Die aanhoor van demonstrasies en volg van wiskundige verwerkings val ook in hierdie kategorie. Leerders benodig hierdie tipe geletterdheid om onafhanklik, dikwels op abstrakte vlak, leerinhoude te bemeester. KATV behels dus die begryp van vakspesifieke woordeskat en leerinhoude en sluit ook die vermoë in om te klassifiseer, argumenteer, vergelyk, op te som, evalueer, afleidings te maak en verskeie afhanklike konsepte sinvol saam te vat. Die klaskamer eis ook veel meer geskrewe uitdrukking in byvoorbeeld opstelle en assesseringstake. Om dus suksesvol in 'n akademiese omgewing te funksioneer verg 'n ander tipe Engels as wat by die snoepie, of langs die sportveld gebruik word. Binne klasverband word 'n leerder dus gekonfronteer met nuwe inhoude en begrippe, wat verwerk en geïnternaliseer moet word. Dikwels is die onderrigtaal bydraend tot die verwarring en wanbegrip wat selfs tot 'n onttrekking en demotivering ten opsigte van skoolwerk lei. Dit is dus ' $n$ fout om te aanvaar dat gespreksvlotheid in 'n taal (selfs die moedertaal) impliseer dat 'n leerder haarself optimaal binne 'n akademiese omgewing gemaklik kan handhaaf.

Hierdie argument is egter ook van toepassing op die onderwyser (Evans \& Cleghorn 2014). Met die veranderende demografie van skole, is verskeie leerkragte genoop om in hulle tweede taal te onderrig. In baie gevalle, is hulle taalvermoë twyfelagtig en beskik hulle self nie oor die nodige instruksionele vlotheid en woordeskat nie. Terselfdertyd ontbreek hul kennis van hul leerders se huistaal en is daar meestal ook min kulturele raakvlakke. Hierdie is 'n onsigbare problematiek wat 'n verskraalde akademiese ervaring tot gevolg het.

$\mathrm{Al}$ is die onderwyser wel bedrewe om effektief in die onderrigtaal te kan skoolhou, bly die klaskameromgewing steeds 'n geweldig komplekse en dinamiese omgewing waar daar daagliks opnuut 'n verhouding tussen onderwyser en kind geskep word en dit, hoofsaaklik, deur middel van taal. Binne hierdie baie genuanseerde verhoudingsruimte, vind veel meer as die oordrag van inligting plaas en bestaan daar ruim geleentheid vir misverstande en konseptuele verwarring. 
Die huidige tendens om kinders uit verskeie taalgroepe en nasionaliteite nou by Engelse 5 skole in te skryf kompliseer verder dié ruimte. Die lesverloop neem langer om almal te akkommodeer as gevolg van die uiteenlopende vlakke van (Engelse) vaardigheid. In 'n poging om elke leerder by te kry en hou, word gereeld herhaal en herfraseer wat beide 'n stadiger pas afdwing. Voorts weet min onderwysers hoe om hierdie taalverskeidenheid as 'n onderrigbate aan te wend. Kodewisseling en transtaling behoort sterk aangemoedig te word as 'n kognitiewe prosesseringstrategie waarop beide die onderwyser en die leerders kan steun, veral tydens komplekse akademiese verduidelikings.

Van die migrante en vlugtelinge in ons land, het nie ander keuses as om hulle kinders te laat onderrig in ' $\mathrm{n}$ taal wat hulle self nie besig nie; Afrikaanssprekende ouers het wel, maar sommiges voer tog ' $n$ andersoortige keuse uit. Behoort dit dan reeds met aanvangsonderrig te begin? Die toetree tot formele onderrig is in alle opsigte 'n nuwe en soms verbouererende ervaring maar deesdae is 'n kind reeds amper sewe jaar oud en moontlik meer opgewasse om merkbare omgewingsveranderinge te verwerk; veral dié wat 'n voorskoolse (Graad R) blootstelling gehad het, mag dit makliker tref.

Cummins $(1979,1992)$ opper die mening dat daar 'n gemeenskaplike, onderliggende bedrewendheid tussen 'n eerste en 'n addisionele taal bestaan - dit wil sê die vaardighede en konsepte wat in die primêre en dus dominante taal geleer is, is wel oordaagbaar indien 'n sterk eerste taal grondslag gelê is. Dit beteken moontlik dat die oorgang vanuit die laerskool, hoërskool toe, dalk makliker is. Aan die ander kant is 'n kind se kultuuridentiteit al meer gevestig op 13 - die gemiddelde toetreeouderdom tot hoërskool.

Taal kan aangeleer word in die onderrigsituasie maar die klaskamer dra dikwels veel meer van die verborge kurrikulum by as wat ouers en onderwysers besef. Om in 'n multikulturele omgewing skool te gaan, bied wel 'n ryk, outentieke Suid-Afrikaanse (waarskynlik middelklas) ervaring wat later in 'n kind se lewe van waarde kan wees, maar kultuurgroepering is sterk eksklusief en "old boys' clubs" selektief oor wie hulle toelaat ten spyte daarvan dat mens saam op skool was.

Afrikaanse skole wat met goeie onderwysers geseën is bied steeds ruim geleentheid vir die aanleer van gehalte Engels. Die veel wyer blootstelling wat televisie en tegnologie deesdae bied, dra ook ruim by om taalbedrewenheid uit te brei.

\section{SAMEVATTING}

Besluite wat ouers neem, raak elke individuele kind anders en ongelukkig is die gevolge nie altyd onmiddellik sigbaar nie. So het my ouers se besluit op 'n Afrikaanse hoërskool verskillend en langtermyn geïmpakteer op elkeen van hulle kinders.

Tye het beslis verander en die baie sterk Engels-Afrikaanse skeidslyn het versag. Die Grondwet beskerm ook nou sprekers van al ons landstale. Onderwysbeleide en inklusiewe wette verseker ook dat enige leerkrag wat nou 'n kind sou betig met "Rooinek, het jy miere in jou broek?" self iewers op 'n rooi tapyt sou kriewel. Daar is nou groter verdraagsaamheid en meer begrip vir diversiteit.

$\mathrm{U}$ vra met reg teen dié tyd wie is ek eintlik en by wie skaar ek my dan in terme van eie identiteit as volwassene? Boer of Brit? Ek kan nie kies nie. Ek visualiseer myself as 'n koesister wat op 'n fyn beblomde Royal Albert piering balanseer - die soethappie so smaaklik soos die tee, so aantreklik soos die porselein. Afrikaans het my hartstaal geword, dis haar musiek en

By 'n voormalige Afrikaanse stadskool wat in Paul Kruger se tyd reeds gestig is, word 13 veskillende tale in die Graad 3 aangetref (Evans \& Cleghorn 2012) 
liriek wat my laat huil en verlang. Dis Afrikaanse gedigte, stories en opvoerings wat my raak; geen Engelse carol kan my land se Kersfees raak beskryf nie en Afrikaanse vloekwoorde tref my tong lekkerder as Engels s'n. Ja, dis Afrikaans wat my as Suid-Afrikaner hier op Afrikabodem gepenwortel het.

Ek kan met gemak in beide tale bid danksy die jare se skriflesings wat ek aangehoor het en saalopeninge waarvoor ek later ook as adjunkhoof voorberei het, maar my eie Bybel sê: "For God so loved the world..." en dit is vir hierdie "world" met sy geweldige verskeidenheid mense, keuses en moontlikhede waarop ouers en betrokke volwassenes by uitstek hul kinders moet voorberei en toerus met verskeie sosiale en tegnologiese vaardighede, 'n suiwer onderskeidingsvermoë, 'n sterk selfbeeld met 'n gewortelde identiteit en 'n soliede taalfundering. Veel meer as net Engels.

\section{SLOT}

Die media werp gereeld die kollig op oproepe van ouers wat aandring om hul kinders in gevestigde Afrikaanse skole te plaas en dan Engels eis as voertaal. Te verstane dat goeie infrastruktuur en 'n skynbare goeie leerervaring in Engels as die opperste paspoort tot sukses beskou word. Hierdie verskynsel is nie alleen die gevolg van ouerlike of gemeenskapsdruk nie, ${ }^{6}$ maar word ook aangevuur deur snelveranderende interkontinentale industrialisasie, ekonomiese migrasie en globalisering (Fair, Seloni \& Song 2010). Taalvoorkeure en gesindhede jeens die waarde van 'n bepaalde taal sal uiteenlopend bly juis omdat Jan Publiek nie voldoende ingelig is ten opsigte van die sosiale en kognitiewe voordele van die aanvanklike ontwikkeling van volle geletterheid in 'n moedertaal nie.

Taaldebatte word reeds heftig gestry in verskeie wêrelddele veral dié wat deur die onverwagse instroming van vlugtelinge geraak word. Klaskamerdemografie is omgewentel met etniese en dialektiese veranderlikes. ' $n$ Deining van nasionalisme, patriotisme en taaltrots is beslis in Wes Europa hoorbaar. Suid-Afrikaanse ouers behoort die voorreg te waardeer wat die huidige nasionale toegevoegde tweetaligheidsbeleid bied asook dat hulle tans nog beskore is om ten minste in die aanvangsjare van skoling, vir hulle kinders moedertaalonderrig te kan eis.

\section{PRIKKELVRAE}

Ek laat u doelbewus sonder netjiese antwoorde, want daar is geen sentrale waarheid oor taal en tale nie, wel ruim geleentheid om die dinamiek en diversiteit wat dit bied te benut.

Ek nooi u uit om tot dié gesprek toe te tree.

- Tot watter mate is 'n individu se persoonlikheid verantwoordelik vir 'n gevoel van uitsluiting binne 'n bepaalde konteks eerder as die sosiale dinamiek?

- Tot watter mate is tersaaklike persoonlike ervarings van vakwetenskaplike waarde?

- Watter stappe behoort tans geneem te word (en deur wie) om 'n bewussyn van taalnasionalisme te kweek onder alle landsburgers?

- Tot watter mate vind 'n verdomliking in die klaskamer plaas omrede Engels as voertaal verkies word?

Alexander (2000); Heugh (2002); Lafon \& Webb (2008); Probyn (2009); Republic of South Africa $(2003,2005)$; Webb (2004). 
- Sou taalhomogeniteit (bv Engels) nie gouer 'n nasionaal-demokratiese samelewing kon bewerkstellig nie?

\section{ERKENNING}

My opregte dank word uitgespreek teenoor Lorraine du Plessis, Koos Malan, Dirk Taljard, Elsabé Taljard, en Johan Wassermann vir waardevolle insette in hierdie uiteindelike bydrae.

\section{BIBLIOGRAFIE}

Alexander, R.J. 2000. Culture and pedagogy: International comparisons in primary education. Oxford: Blackwell.

Bunyi, G. 1999. Rethinking the place of African indigenous languages in African education. International Journal of Educational Development, 19(4-5):337-350.

Crystal, D. 2003. English as a global language. Cambridge: Cambridge University Press.

Cummins, J. 1979. Linguistic interdependence and the education of bilingual children. Review of Educational Research, 49:222-251.

Cummins, J. 1992. Language proficiency, bilingualism, and academic achievement. In Richard-Amato \& Snow (eds). The multicultural classroom: Readings for content area teachers. White plains: New York, pp. 16-26.

Cummins, J. \& Hornberger, N. (eds). 2007. 2nd edition. Encyclopaedia of language and education. New York: Springer.

Evans, R. \& Cleghorn, A. 2012. Complex classroom encounters - a South African perspective. Rotterdam: Sense Publishers.

Evans, R. \& Cleghorn, A. 2014. Parental perceptions: a case study of school choice amidst language waves. South African Journal of Education, 34(2):1-19.

Farr, M. Seloni, L. \& Song, J. (eds). 2010. Ethnolinguistic diversity and education: Language, literacy, and culture. New York:Routledge.

Heugh, K., Siegrühn, A. \& Plüddemann, P. (eds). 1995. Multilingual education for South Africa. Johannesburg: Heinemann.

Heugh, K. 2002. Teacher education issues: implementation of a new curriculum and language in education policy. In N. Alexander (ed.) Mother tongue-based bilingual education in South Africa: The dynamics of implementation. Multilingualism network \& Cape Town: PRAESA, pp. 137-158.

Holmarsdottir, H.B. 2005. From policy to practice: A study of the implementation of the language-ineducation policy (LiEP) in three South African primary schools. PhD dissertation, University of Oslo. http://www.duo.uio.no/publ/pfi/2005/99096/ Holmarsdottir_avhandling

Joubert, I. Bester, M., Meyer, E. \& Evans, R. 2013. Literacy in the Foundation Phase. Pretoria: Van Schaik Publishers.

Lafon, M. \& Webb, V. 2008. (eds). Standardisation of African Languages - Language social realities. Johannesburg: Institute Francais d'Afrique du Sud.

Malan, J.J. 2012. 'n Oorweging van die sosiopolitieke kragte wat inwerk op die betekenis en toepassing van die diskresionêre taalklousule van die Suid- Afrikaanse grondwet. LitNet Akademies Jaargang $9(1)$.

Malan, J.J. 2014. An analysis of the legally protectable interests pertaining to language.Tydskrif vir die Suid-Afrikaanse Reg (TSAR) / Journal of South African Law, pp. 66-84. http://repository.up.ac.za/ handle/2263/40939? show=full [5 Julie 2017].

Probyn, M. 2009. 'Smuggling the vernacular into the classroom': Conflicts and tensions in classroom code switching in township/rural schools in South Africa. International Journal of Bilingual Education and Bilingualism, 12(2):123-136.

Republic of South Africa. 1996. Constitution of South Africa.

Republic of South Africa. 2001. Education Whitepaper 5 on Early Childhood Education: meeting the challenge of early childhood development in South Africa. Pretoria: Department of Education. 
Republic of South Africa. 2003. Revised National Curriculum Statement Grades R-9, Teachers' Guide for the Development of Learning Programmes (Languages). Pretoria: Department of Education.

Republic of South Africa. 2005. National Curriculum Statement. Pretoria: Department of Education.

Republic of South Africa. 2010. The status of the language of learning and teaching in South African public schools. Pretoria: Department of Basic Education.

Republic of South Africa. 2011. Annual National Assessments Report. Pretoria: Department of Basic Education.

Thomas, W.P. \& Collier, V.P. 2011. Drs. Thomas and Collier share the educational implications of their research on dual language programs. ESL Globe, 8(1):1-2. Raleigh, NC: North Carolina State University.

Tollefson, J.W. 1991. Planning language, planning inequality: Language policy in the community. London: Longman.

Tollefson, J.W. \& Tsui, A.B.M. (eds). 2004. Medium of instruction policies: Which agenda? Whose agenda? Mahwah, NJ: Lawrence Erlbaum.

Webb, V.N. 2004. African languages as media of instruction in South Africa: Stating the case. Language Problems and Language Planning, 28:147-73.

Wong-Fillmore, L. 1991. When learning a second language means losing the first. Early Childhood Research Quarterly, 6:323-46. 
